dr inż. Tomasz Kądziotka

Instytut Techniczny, Państwowej Wyższej

Szkoły Zawodowej w Nowym Saczu

dr inż. Stawomir Kowalski

mgr inz. Dariusz Smolarski

Politechnika Krakowska

\title{
Analiza porównawcza wrażliwości dźwigniowych hamulców kolejowych
}

\begin{abstract}
$W$ artykule przedstawiono analizę porównawcza badania wrażliwości dźwigniowych hamulców kolejowych. Porównania dokonano badajac wrażliwość szczękowych hamulców kolejowych z hamulcami tarczowymi, które stosowane sq w nowoczesnych szybkobieżnych wagonach kolejowych.
\end{abstract}

\section{Oznaczenia}

$X_{i}, Y_{i}$ - współrzędne i - tej par kinematycznej,

$S_{A E}$ - człon o zmiennym wymiarze (np. siłownik pneumatyczny),

$F_{c i}$ - funkcja celu i - tego członu,

$\mu \quad-$ wskaźnik wrażliwości mechanizmu.

\section{Wstęp}

W obecnym czasie, gdzie prędkość pociągów ciągle wzrasta zachodzi potrzeba zastosowania odpowiednich układów hamulcowych, które umożliwią zatrzymanie pociagu $\mathrm{w}$ pożądanym czasie. Hamulce szczękowo - bębnowe z racji swej skomplikowanej budowy nie spełniaja kryteriów dostosowania do zwiększającej się prędkości pociagów. Dlatego chcąc spełnić wymogi bezpieczeństwa we współczesnych pociagach zastosowano hamulec tarczowy, który przez zastosowanie mniejszej ilości dźwigni mógł spełnić zadane wielkości.

W pracy został porównany klasyczny hamulec szczękowy z hamulcem tarczowym. Została zbadana wrażliwość kinematyczna obu rozwiązań. Poprzez analizę badań zostały opracowane wnioski, które dały jasny obraz dotyczący bezpieczeństwa podróżujących pociagami.

\section{Przegląd rozwiązań tarczowych hamulców wa- gonowych}

W pojazdach kolejowych stosowane są dwa rodzaje hamulców tarczowych:

- z tarczami umieszczonymi na osiach zestawów kolowych (rys 1, rys 2).- rozwiązanie to jest eksploatowane najczęściej w wózkach tocznych i umożliwia zastosowanie do trzech zespołów hamulcowych na jednej osi,

- z tarczami (pierścieniami ciernymi) umieszczonymi na kołach pojazdu (rys 3, rys 4)- rozwiązanie to najczęściej stosowane jest w pojazdach trakcyjnych, gdzie nie ma miejsca na zastosowanie wcześniej opisanego typu z powodu lokalizacji między kołami zespołów napędowych. Warunkiem stosowania pierścieni ciernych na kołach jest zastosowanie kół monoblokowych. Pierścienie cierne w omawianym typie montowane są z obu stron tarcz kół jezdnych [5].
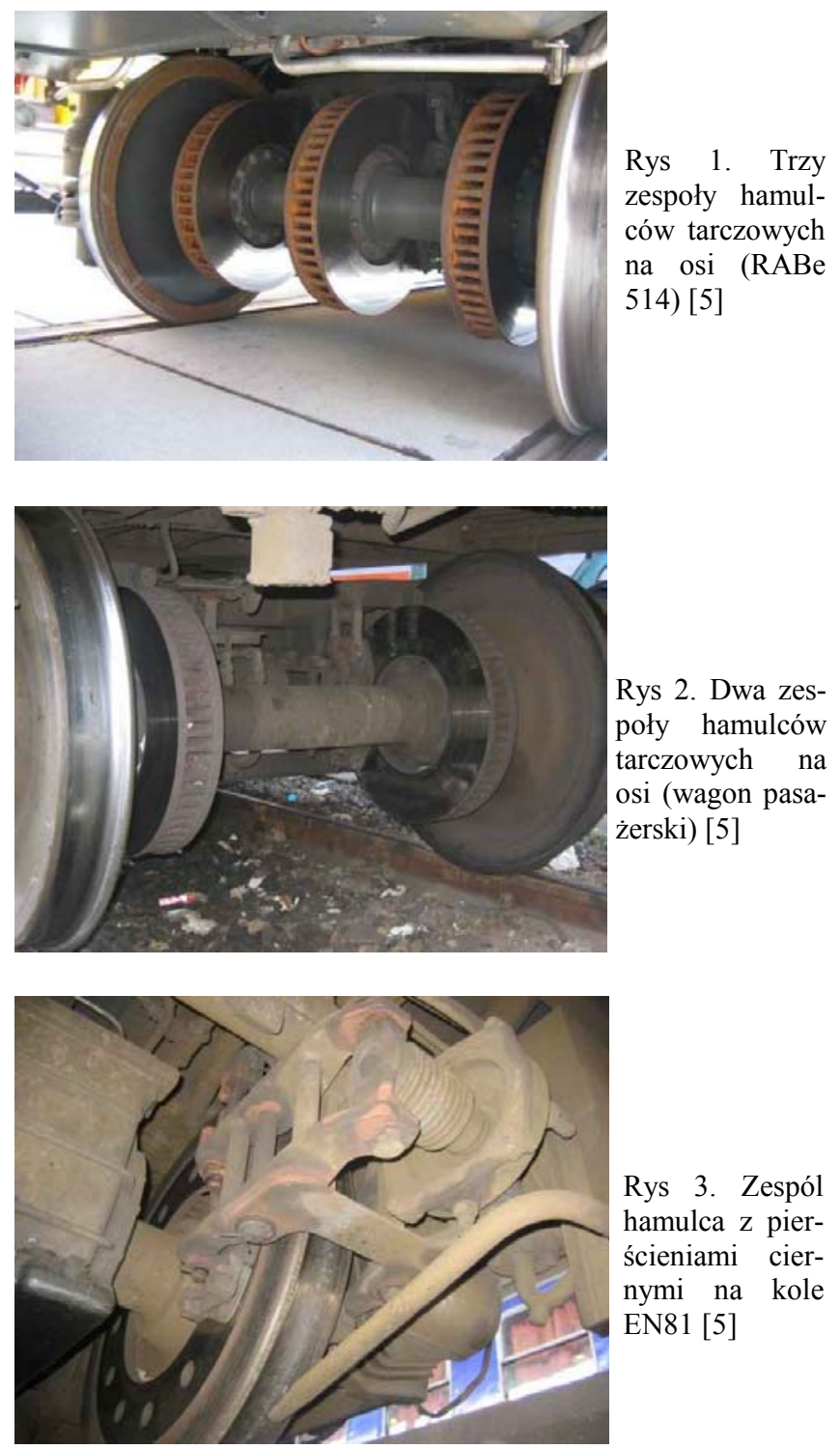


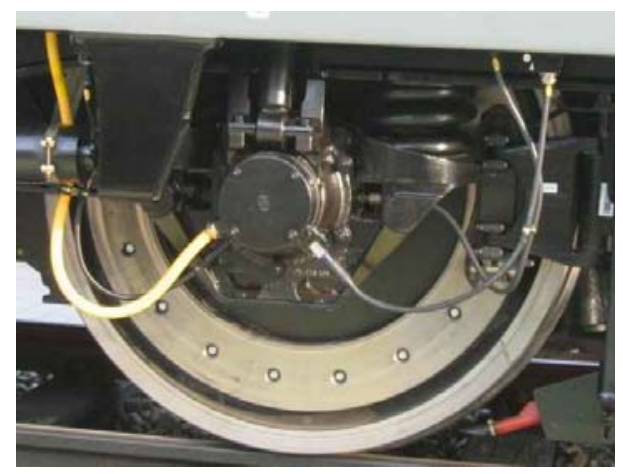

Rys 4. Pierścień cierny zewnętrzny na kole Bombardier TRAXX [5]

Tarcze hamulcowe wykonane są z żeliwa lub staliwa [5]. Podczas hamowania na styku trących o siebie elementów ciernych powstaje wysoka temperatura (zmiana energii kinetycznej na cieplną) dochodząca nawet do $250{ }^{\circ} \mathrm{C}$. W celu zapewnienia możliwe najlepszego chłodzenia, tarcze posiadają specjalne układ otworów / żeber pełniących rolę radiatorów - zwiększenie powierzchni oddającej ciepło (rys 5). Okładziny cierne montowane w obsadach szczęk wykonywane sa $\mathrm{z}$ tworzyw organicznych lub niekiedy ze spieków i również w nich występują specjalne nacięcia (rowki) poprawiające chłodzenie. Tarcze (pierścienie cierne) montowane na tarczach kół jezdnych mają mniej skuteczne chłodzenie, gdyż powstające ciepło jest oddawane częściowo na koło jezdne, a częściowo przez wewnętrzne użebrowanie pierścienia ciernego stykającego się z tarczą koła. Stopień rozgrzewania się elementów trących o siebie jest zależny od siły docisku oraz prędkości jazdy.

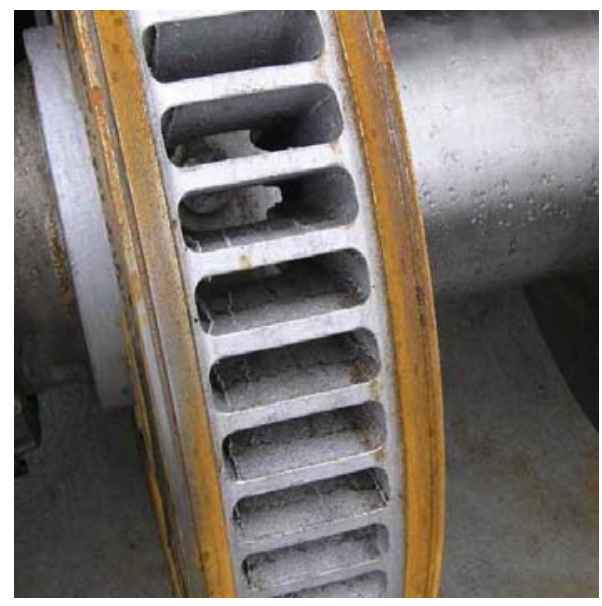

Rys. 5. Użebrowanie tarczy hamulcowej dla celów chłodzenia [5]

\section{Analiza kinematyczna kolejowych hamulców tarczowych}

W celu dokonania analizy kinematycznej tarczowych hamulców kolejowych, został sporządzony ich schemat kinematyczny (rys. 6) i strukturalny (rys. 7).
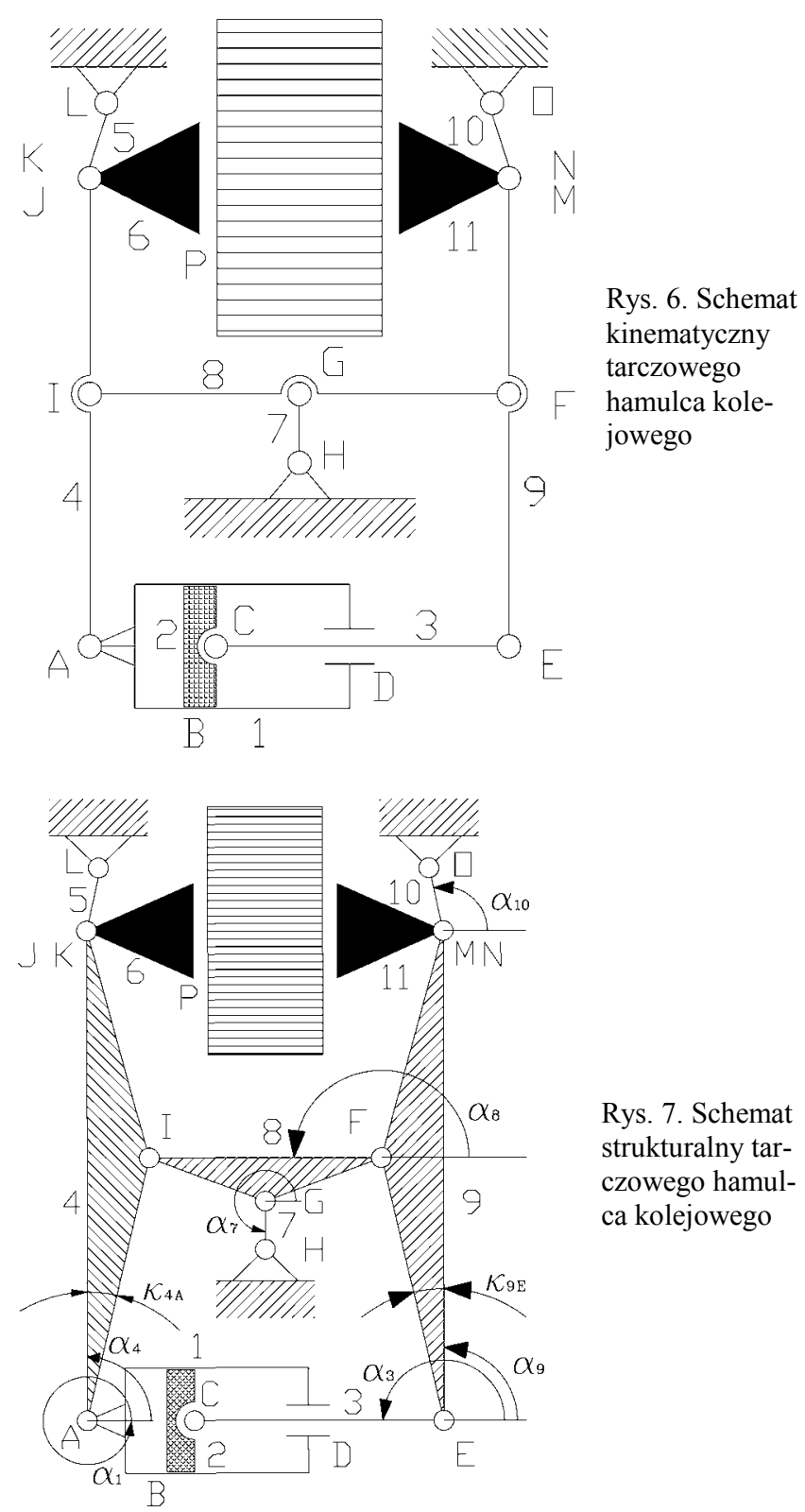

Rys. 7. Schemat strukturalny tarczowego hamulca kolejowego

\subsection{Ruchliwość mechanizmu}

Ruchliwość mechanizmu [4] wyznaczono zgodnie ze wzorem:

$$
W^{\prime}=3 n_{r}-2 p_{5}-p_{4}
$$

gdzie:

$\mathrm{n}_{\mathrm{r}}$ - ilość członów ruchomych,

$\mathrm{p}_{5}$ - ilość par kinematycznych klasy piątej (jeden stopień ruchliwości),

$\mathrm{p}_{4}$ - ilość par kinematycznych klasy czwartej (dwa stopnie ruchliwości).

$\mathrm{W}$ badanym mechanizmie:

$\mathrm{n}_{\mathrm{r}}=11$,

$\mathrm{p}_{5}=15$,

$\mathrm{p}_{4}=0$.

Stąd ruchliwość mechanizmu $W^{\prime}=3$. Mechanizm posiada więc trzy stopnie swobody. 
Ponieważ układ mechaniczny hamulca tarczowego jest tak skonstruowany, że ma możliwość samoczynnego dopasowania się do tarczy hamulcowej, ruchliwość hamulca należy obliczyć zakładając że szczęka stykająca się z tarczą hamulcową tworzy parę kinematyczną. Wówczas:

$\mathrm{n}_{\mathrm{r}}=11$,

$\mathrm{p}_{5}=16$,

$\mathrm{p}_{4}=0$.

Stąd ruchliwość mechanizmu $\mathrm{W}^{\prime}=1$. Mechanizm posiada więc jeden stopień ruchliwości.

\subsection{Analiza kinematyczna tarczowego hamulca kolejowego}

Badany mechanizm klasy III składa się z zespołu kinematycznego klasy III szeregu 3. Poniżej przedstawiono sposób wyznaczenia położenia członów i współrzędnych par kinematycznych. Obliczeń dokonano przyjmując założenie, że podczas wysuwu siłownika para kinematyczna A pozostaje nieruchoma tym samym tylko jedna szczęka zaczyna zbliżać się do tarczy hamulcowej (pierwsza faza ruchu). Po zetknięciu szczęki $10 \mathrm{z}$ tarczą hamulcową para kinematyczna E (rys. 7) pozostaje nieruchoma a ruch przejmuje dźwignia 4 napędzająca szczękę 6 (druga faza ruchu).

$\left\{\begin{array}{l}X_{E}=X_{A 1}+S_{A E} \cdot \cos \left(\alpha_{3}\right) \\ Y_{E}=Y_{A 1}+S_{A E} \cdot \sin \left(\alpha_{3}\right)\end{array}\right.$,

gdzie:

$\mathrm{X}_{\mathrm{A} 1}, \mathrm{Y}_{\mathrm{A} 1}$ - współrzędne pary kinematycznej A podczas pierwszej fazy ruchu,

$\left\{\begin{array}{l}X_{E}+l_{E M} \cdot \cos \left(\alpha_{9}\right)+l_{M O} \cdot \cos \left(\alpha_{10}\right)-X_{0}=0 \\ Y_{E}+l_{E M} \cdot \sin \left(\alpha_{9}\right)+l_{M O} \cdot \sin \left(\alpha_{10}\right)-Y_{0}=0\end{array} \Rightarrow \alpha_{9}, \alpha_{10}\right.$

$\left\{\begin{array}{l}X_{F}=X_{E}+l_{E F} \cdot \cos \left(\alpha_{9}+\kappa_{9 E}\right) \\ Y_{F}=Y_{E}+l_{E F} \cdot \sin \left(\alpha_{9}+\kappa_{9 E}\right)\end{array}\right.$,

$\left\{\begin{array}{l}X_{F}+l_{F G} \cdot \cos \left(\alpha_{8}+\kappa_{8 F}\right)+l_{G H} \cdot \cos \left(\alpha_{7}\right)-X_{H}=0 \\ Y_{F}+l_{F G} \cdot \sin \left(\alpha_{8}+\kappa_{8 F}\right)+l_{G H} \cdot \sin \left(\alpha_{7}\right)-Y_{H}=0\end{array} \Rightarrow \alpha_{7}, \alpha_{8}\right.$,

$\left\{\begin{array}{l}X_{G}=X_{F}+l_{F G} \cdot \cos \left(\alpha_{8}+\kappa_{8 F}\right) \\ Y_{G}=Y_{F}+l_{F G} \cdot \sin \left(\alpha_{8}+\kappa_{8 F}\right)\end{array}\right.$,

$\left\{\begin{array}{l}X_{A 2}=X_{E}+S_{A E} \cdot \cos \left(\alpha_{1}\right) \\ Y_{A 2}=Y_{E}+S_{A E} \cdot \sin \left(\alpha_{1}\right)\end{array}\right.$, gdzie:

$\mathrm{X}_{\mathrm{A} 2}, \mathrm{Y}_{\mathrm{A} 2}$ - współrzędne pary kinematycznej A podczas drugiej fazy ruchu,

$\left\{\begin{array}{l}X_{A 2}+l_{A 2 J} \cdot \cos \left(\alpha_{4}\right)+l_{J L} \cdot \cos \left(\alpha_{5}\right)-X_{L}=0 \\ Y_{A 2}+l_{A 2 J} \cdot \sin \left(\alpha_{4}\right)+l_{J L} \cdot \sin \left(\alpha_{5}\right)-Y_{L}=0\end{array} \Rightarrow \alpha_{4}, \alpha_{5},(8)\right.$

$\left\{\begin{array}{l}X_{I}=X_{A 2}+l_{A I} \cdot \cos \left(\alpha_{4}-\kappa_{4 A}\right) \\ Y_{I}=Y_{A 2}+l_{A I} \cdot \sin \left(\alpha_{4}-\kappa_{4 A}\right)\end{array}\right.$,

$\left\{\begin{array}{l}X_{J}=X_{A 2}+l_{A J} \cdot \cos \left(\alpha_{4}\right) \\ Y_{J}=Y_{A 2}+l_{A J} \cdot \sin \left(\alpha_{4}\right)\end{array}\right.$.

W celu określenia drogi jaką musi pokonać szczęka by mogła zetknąć się z tarczą hamulcową wyznaczono tak zwaną funkcję celu (11):

$F_{c}=b-\sqrt{\left(X_{J}-X_{M}\right)^{2}+\left(Y_{J}-Y_{M}\right)^{2}} \rightarrow 0$

gdzie:

b - grubość tarczy hamulcowej.

Po podstawieniu wymiarów członów i określeniu współrzędnych par kinematycznych przyostojowych i przy założeniu, że kąt $\alpha_{1}=\alpha_{3}+180^{\circ}$ (rys. 7) sporządzono wykres funkcji celu w postaci:

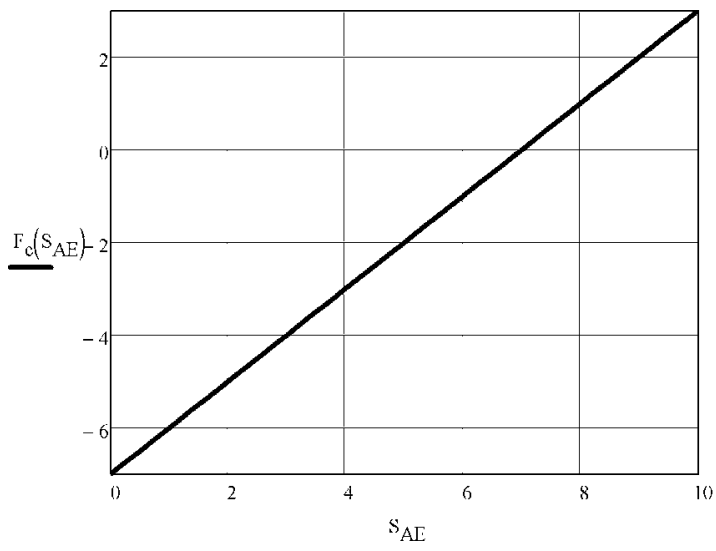

Rys. 8. Wykres funkcji celu

\subsection{Wrażliwość kinematyczna}

Ze względu na luz, jaki występuje między sworzniem a panewką, sworzeń może zajmować różne położenia w otworze [3]. Odległość między osiami sworzni więc zwiększa się lub zmniejsza. Wyznaczono funkcję celu odpowiadające granicznym położeniom sworznia w panewce. Tworzą one wstęgę funkcji celu, wewnątrz której przebiega funkcja celu odpowiadająca rzeczywistemu położeniu sworznia. Na rys. 9 przedstawiono wstęgę funkcji celu, wewnątrz której linią kreskową zaznaczono funkcję celu odpowiadającą nominalnym wymiarom mechanizmu. 


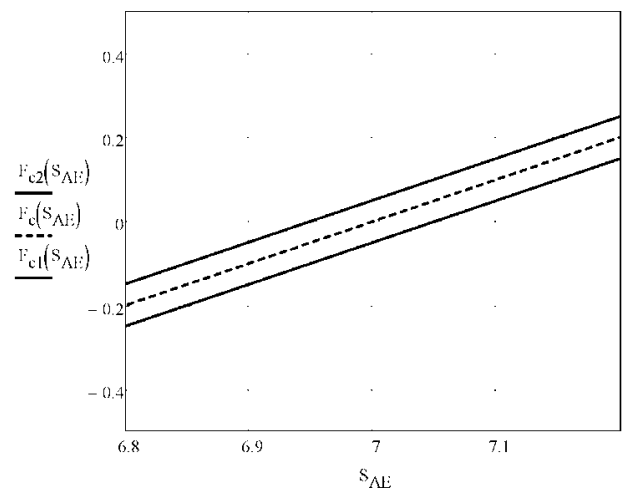

Rys. 9. Wstęga funkcji celu dla pasowania H8/e8

Wyznaczono wskaźnik wrażliwości mechanizmu $[1$, , zgodnie z wzorem

$$
\mu=1-\frac{L}{\Delta S_{A E}}
$$

gdzie:

$\mu$ - wskaźnik wrażliwości mechanizmu,

L - odległość między punktami przecięcia osi odciętych przez graniczne funkcje celu wstęgi,

$\Delta \mathrm{S}_{\mathrm{AE}}$ - zakres ruchu członu napędowego do chwili zetknięcia się klocków z tarczą hamulcową (funkcja celu przecina oś odciętych).

Dla rozpatrywanego rodzaju pasowań H8/e8 otrzymano $\mathrm{L}=0,1 \mathrm{~mm}, \Delta \mathrm{S}_{\mathrm{AE}}=7 \mathrm{~mm}$. Stąd wrażliwość mechanizmu $\boldsymbol{\mu}=\mathbf{0 , 9 8 6}(\boldsymbol{\mu}=\mathbf{9 8 , 6} \%)$.

\section{Analiza wrażliwości szczękowo - kołowego ha- mulca kolejowego}

Badanie wrażliwości szczękowo - kołowego hamulca kolejowego zostały opisane w [3]. Dlatego w niniejszym artykule zostanie zaprezentowany tylko szkic obliczeń.

Przeprowadzając analizę kinematyczną zauważono, że mechanizm hamulca składa się czterech analogicznych zespołów (rys. 10) dlatego badania przeprowadzono dla jednego (rys. 11).

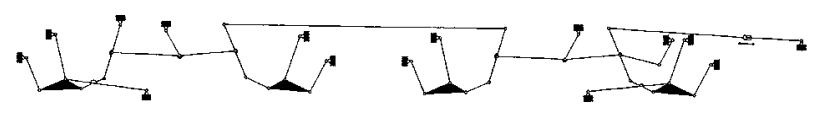

Rys. 10. Schemat kinematyczny mechanizmu uruchamiania hamulców kolejowych

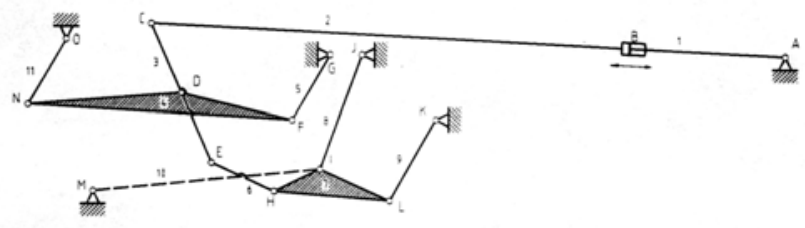

Rys. 11. Schemat kinematyczny mechanizmu hamulca kolejowego
Po wyznaczeniu współrzędnych par kinematycznych i określeniu położenia członów, przyjmując pasowanie H8/e8, postępując w sposób analogiczny jak w rozdziale 3.3 otrzymano wstęgę funkcji celu (rys. 10)

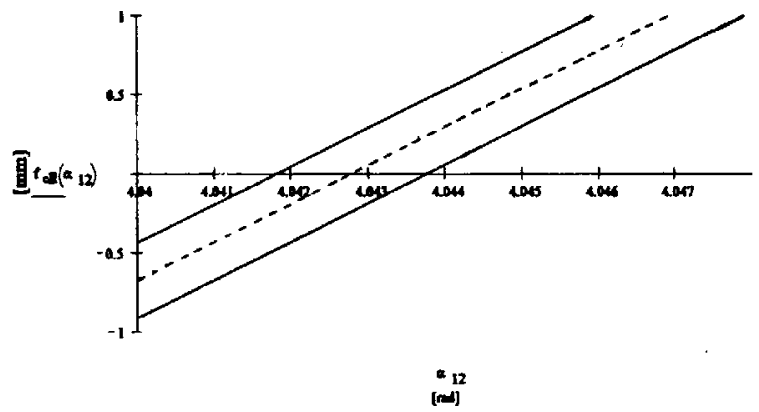

Rys. 12. Wstęga funkcji celu dla pasowania H8/e8

Analizując rys. 12 i znając zakres ruchu członu napędowego (w badanym przypadku $\Delta \alpha_{1}=0,032 \mathrm{rad}$, L $=0,0021 \mathrm{rad}$ ), określono wrażliwość hamulców kolejowych $\mu=0,934(\mu=93,4 \%)$.

\section{Podsumowanie i wnioski końcowe}

Porównując wyniki otrzymane $\mathrm{w}$ rozdziale $3.3 \mathrm{z}$ wynikami z rozdziału 4, stwierdzić można, że wrażliwość kinematyczna tarczowego hamulca wagonowego wynosi 98,6 \%, natomiast wrażliwość hamulca szczękowo - kołowego równa się 93,4 \% [3].

Analiza ta jasno stwierdza przydatność w/w hamulców. Przez zmniejszenie ilości dźwigni i łączących je par kinematycznych (sworzeń - panewka) zwiększono wrażliwość kinematyczną o 5,2\% tym samym została zwiększona sprawność kinematyczna hamulca. Niestety pociagło to za sobą zwiększenie ilości siłowników pneumatycznych co spowodowało zmniejszenie niezawodności układu.

\section{Liter at ura}

[1] Kqdziotka T., Wptyw struktury i doktadności wykonania czlonów na wrażliwość wag uchylnych, rozprawa doktorska, Akademia Techniczno - Humanistyczna, Bielsko - Biata 2006.

[2] Mtynarski T., Uogólniona metoda analityczna analizy kinematycznej mechanizmów płaskich, Monografia 168, Politechnika Krakowska, Kraków 1994.

[3] Mtynarski T., Kadziotka T., Romaniak K., Badanie wrażliwości kinematyczne układów hamulcowych wagonów kolejowych, Zeszyty Naukowe Politechniki Ślaskiej, Seria Transport, Wydawnictwo Politechniki Ślaskiej, Gliwice 1999.

[4] Morecki A., Knapczyk J., Kędzior K., Teoria mechanizmów i manipulatorów, Wydawnictwo WNT, Warszawa 2002.

[5] Górowski M., Transport szynowy niezależna strona informacyjna,http://www.transportszynowy.pl/kolhamulcetarczowe.php 